\title{
openheart In-hospital treatment and outcomes of heart failure in specialist and non-specialist services: a retrospective cohort study in the elderly
}

\author{
Kishan R Parmar, ${ }^{1,2}$ Philip Y Xiu, ${ }^{1,3}$ Muhibbur R Chowdhury, ${ }^{1}$ Ekta Patel, ${ }^{4}$ \\ Maurice Cohen ${ }^{1}$
}

To cite: Parmar KR, Xiu PY, Chowdhury MR, et al. In-hospital treatment and outcomes of heart failure in specialist and non-specialist services: a retrospective cohort study in the elderly. Open Heart 2015;2:e000095 doi:10.1136/openhrt-2014000095

Received 26 February 2014 Revised 9 April 2015 Accepted 28 April 2015

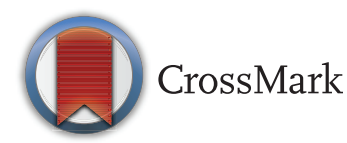

\footnotetext{
${ }^{1}$ Department of Elderly Medicine, North Middlesex University Hospital, London, UK

${ }^{2}$ Department of Elderly Medicine, Hillingdon Hospital, London, UK ${ }^{3}$ Department of Cardiology, Royal Brompton Hospital, London, UK

${ }^{4}$ Department of Elderly Medicine, Chelsea and Westminster Hospital, London, UK
}

Correspondence to Dr Kishan R Parmar; kishan.parmar@doctors. org.uk

\section{ABSTRACT \\ Background: Heart failure is common in the elderly and is associated with high rates of hospitalisation, readmission and mortality. International guidelines however are not frequently implemented in this population.}

Methods: We retrospectively studied the clinical profile, investigations, treatment on discharge, length of hospital stay, readmission rate and mortality in 261 patients, aged $\geq 75$ years, with a discharge diagnosis of heart failure. Clinical frailty was estimated using the Canadian Study of Health and Aging clinical frailty scale.

Results: Hypertension (64\%), atrial fibrillation $(50.6 \%)$ and ischaemic heart disease $(46 \%)$ were common, and $75.6 \%$ of patients were clinically vulnerable or frail. $23.5 \%$ of admitters had an inpatient echocardiogram and $20 \%$ of patients had at least one readmission episode for heart failure. On discharge, $64.6 \%$ of admissions were treated with an ACE inhibitor or angiotensin II receptor antagonist, $49.3 \%$ with a $\beta$ blocker and $28.7 \%$ with an aldosterone receptor antagonist (ARA). Patients discharged from cardiology wards were more likely to receive a $\beta$ blocker $(p<0.05)$ versus care of elderly (COE) wards and readmitters were more likely to receive an ARA $(p<0.05)$ versus patients with a single admission. In total, 34 inpatient deaths were recorded $(13 \%)$ and 80 deaths $(30.7 \%)$ were recorded long-term (median follow-up 337 days). Long-term mortality was significantly lower in single admitters versus readmitters $(p<0.0001)$ and in those managed on cardiology wards versus COE wards $(p<0.05)$.

Conclusions: Compared with patients hospitalised on geriatric wards, those admitted to cardiology units were discharged more frequently with recommended medications and had a lower long-term mortality.

\section{INTRODUCTION}

Heart failure, a complex cardiac syndrome, is increasingly being recognised as a geriatric syndrome as it is more common in the elderly. ${ }^{1}$ In the UK, heart failure is associated

\section{KEY MESSAGES}

What is already known about this subject?

- Heart failure is associated with high rates of hospitalisation and mortality, particularly in the elderly where treatments for heart failure remain suboptimal.

What does this study add?

- This study confirms that elderly patients admitted with heart failure are often clinically vulnerable or frail, and supports the poor prognosis of elderly patients hospitalised with heart failure. Access to specialist cardiology input may influence the use of guidance-indicated treatment which may improve survival.

How might this impact on clinical practice?

- Elderly patients admitted with heart failure should be managed using a multidisciplinary approach involving geriatricians and cardiologists.

with high rates of hospitalisation, healthcare costs and mortality, and is thought to affect $12-14 \%$ of men and women over 75 years. ${ }^{2}$ It is one of the most common reasons for medical admission, readmission and hospital bed occupancy, costing the NHS $£ 625$ million per year. ${ }^{3}$ With improved diagnosis and prolonged survival, the incidence and prevalence of heart failure in the elderly will continue to rise, with huge economic consequences for healthcare systems.

Recognising the requirement to improve heart failure outcomes, the National Institute for Care Excellence (NICE) has developed guidelines for the management of heart failure, ${ }^{4}$ and the National Heart Failure (NHF) audit ${ }^{3}$ was launched to assess achievements against NICE guidelines. The Euro Heart Failure Survey (EHFS) was also launched and has provided details regarding heart failure outcomes in the elderly. ${ }^{5}$ 
Reports from the NHF audit and EHFS demonstrate that treatment for heart failure remains suboptimal and that patient outcomes remain poor, particularly in the elderly. ${ }^{3}$ Age and access to specialist cardiology input appear to be important predictors of mortality, and therefore the dual role of geriatricians and cardiologists in the delivery of effective heart failure care has been proposed. ${ }^{6}$ Our aim was to retrospectively assess not only heart failure activity in the over-75s in a London university hospital, but also standards of practice and patient outcomes against current evidence.

\section{METHODS}

All patients at North Middlesex University Hospital (NMUH), aged $\geq 75$ years, with a discharge diagnosis of heart failure (based on HRG coding), over a 19-month period, were identified, after approval from the research and ethics committee. The clinical information portal (CIP), a software used at NMUH, was subsequently used to retrospectively collect information on patient demographics, investigations, treatments on discharge and patient outcomes, including length of hospital stay (LOS), readmission, mortality and follow-up. Clinical frailty was also estimated, using the Canadian Study of Health and Aging (CSHA) 7 point clinical frailty scale (category 1: very fit-robust, active, energetic, well motivated and fit; category 2: well-without active disease, but less fit than people in category 1; category 3: wellwith treated comorbid disease-disease symptoms are well controlled compared with those in category 4; category 4: vulnerable-although not frankly dependent, these people commonly complain of disease symptoms; category 5: mildly frail-limited dependence on others for instrumental activities of daily living; category 6: moderately frail-help is needed with both instrumental and non-instrumental activities of daily living; category 7: severely frail—completely dependent on others for activities of daily living or terminally ill). ${ }^{7}$ Patients initially identified for the study without discharge summaries on CIP were excluded from the study. Differences between data were tested using the two-tailed unpaired Student t test, or two-tailed Fisher's exact test, taking $\mathrm{p}<0.05$ to be statistically significant.

\section{RESULTS}

\section{Patient demographics}

In total, 261 patients were included in the study, with a mean age of 79 years. Women represented $51 \%$ of the study population, and males represented $49 \%$. Baseline clinical characteristics and clinical frailty are given in table 1 . The most common comorbidities in the study population were hypertension $(64 \%)$, atrial fibrillation $(50.6 \%)$ and ischaemic heart disease $(46 \%)$, respectively; $75.6 \%$ of patients included in the study had a CSHA clinical frailty score of $\geq 4$ and were clinically vulnerable or frail.
The 261 patients had 328 admission episodes for heart failure, of which $261(76.6 \%)$ were first admission episodes and $67(20.4 \%)$ were readmission episodes. A total of 212 patients had a single admission episode (single admitters group) and 49 patients had at least one readmission episode for heart failure (readmitters group), of which $68.7 \%$ were within 30 days of discharge. 201 admissions $(61.3 \%)$ were managed on care of elderly (COE) wards, $36(11 \%)$ on cardiology wards and $91(27.7 \%)$ on general medical wards.

There were no significant differences in comorbidities between the single admitters group and the readmitters group (table 2). Type 2 diabetes mellitus, however, was significantly more common in patients managed on cardiology wards versus COE wards. There were no significant differences in clinical frailty in the single admitters group versus the readmitters group, or in patients admitted to cardiology wards versus COE wards (table 3).

\section{Investigations}

In total, $23.5 \%$ of admissions had an inpatient echocardiogram (table 4). Left ventricular ejection fraction (LVEF) was significantly lower in the readmitters group versus the single admitters group $(44.1 \%$ vs $49.6 \%$, $\mathrm{p}<0.05$ ) (table 5). More patients admitted to cardiology wards underwent inpatient echocardiography compared with those admitted to $\mathrm{COE}$ wards, although this was not statistically significant (33.3\% vs $22.4 \%$ ) (table 5$)$.

\section{Treatment on discharge}

In total, $64.6 \%$ of heart failure admitters were discharged on an ACE inhibitor or angiotensin II receptor blocker (ARB), $49.3 \%$ on a $\beta$ blocker, $28.7 \%$ on an aldosterone receptor antagonist (ARA) and $81.4 \%$ on a loop diuretic (table 4). When comparing single

\begin{tabular}{|c|c|c|c|}
\hline Comorbidities & $\begin{array}{l}\text { All patients } \\
(n=261)(\%)\end{array}$ & $\begin{array}{l}\text { CSHA } \\
\text { frailty } \\
\text { scale }\end{array}$ & $\begin{array}{l}\text { All patients } \\
(n=261)(\%)\end{array}$ \\
\hline Severe anaemia* & 20.7 & 1 & 0 \\
\hline eGFR $<45 \mathrm{~mL} / \mathrm{min}$ & 26.8 & 2 & 0.8 \\
\hline COPD & 23 & 3 & 23.6 \\
\hline T2DM & 36.4 & 4 & 35 \\
\hline Stroke & 15.7 & 5 & 18.5 \\
\hline IHD & 46 & 6 & 12.6 \\
\hline HTN & 64 & 7 & 9.5 \\
\hline AF & 50.6 & & \\
\hline $\begin{array}{l}\text { Moderate/severe } \\
\text { AS }\end{array}$ & 11.1 & & \\
\hline $\begin{array}{l}\text { Moderate/severe } \\
\text { MR }\end{array}$ & 10.3 & & \\
\hline \multicolumn{4}{|c|}{$\begin{array}{l}{ }^{*} \mathrm{Hb}<11.5 \mathrm{~g} / \mathrm{dL} \text { in men, }<10.5 \mathrm{~g} / \mathrm{dL} \text { in women. } \\
\text { AF, atrial fibrillation; AS, aortic stenosis; COPD, chronic } \\
\text { obstructive pulmonary disease; CSHA, Canadian Study of Health } \\
\text { and Ageing; eGFR, estimated glomerular filtration rate; HTN, } \\
\text { hypertension; IHD, ischaemic heart disease; MR, mitral } \\
\text { regurgitation; T2DM, type } 2 \text { diabetes mellitus. }\end{array}$} \\
\hline
\end{tabular}


Table 2 Comparison of comorbidities

\begin{tabular}{|c|c|c|c|c|c|c|}
\hline Comorbidities & $\begin{array}{l}\text { Single admitters } \\
(n=212)(\%)\end{array}$ & $\begin{array}{l}\text { Readmitters } \\
(n=49)(\%)\end{array}$ & p Value & $\begin{array}{l}\text { COE } \\
(n=201)(\%)\end{array}$ & $\begin{array}{l}\text { Cardiology } \\
(n=36)(\%)\end{array}$ & p Value \\
\hline Severe anaemia* & 18.9 & 28.6 & NS† & 21.2 & 30 & NS† \\
\hline eGFR $<45 \mathrm{~mL} / \mathrm{min}$ & 26.8 & 26.5 & NSt & 27.6 & 26.7 & NSt \\
\hline COPD & 23.1 & 22.4 & NSt & 21.2 & 13.3 & NS† \\
\hline T2DM & 35.4 & 40.8 & NSt & 32.3 & 53.3 & $<0.05 \dagger$ \\
\hline Stroke & 16 & 14.3 & NS† & 16.5 & 10 & NSt \\
\hline IHD & 43.4 & 57.1 & NSt & 50.6 & 63.3 & NSt \\
\hline HTN & 64.2 & 63.3 & NSt & 65.8 & 66.6 & NSt \\
\hline $\mathrm{AF}$ & 51.4 & 46.9 & NSt & 50.6 & 43.3 & NSt \\
\hline
\end{tabular}

${ }^{*} \mathrm{Hb}<11.5 \mathrm{~g} / \mathrm{dL}$ in men, $<10.5 \mathrm{~g} / \mathrm{dL}$ in women.

tp Value calculated using 2-tailed Fisher's exact test.

$\mathrm{AF}$, atrial fibrillation; $\mathrm{COE}$, care of elderly; COPD, chronic obstructive pulmonary disease; eGFR, estimated glomerular filtration rate; HTN,

hypertension; IHD, ischaemic heart disease; NS, not significant; T2DM, type 2 diabetes mellitus.

admitters with readmitters, there was no significant difference in the prescription of ACE inhibitors/ARB, $\beta$ blockers or loop diuretics; however, there was a significant increase in the prescription of an ARA in the readmitters group $(36.2 \%$ vs $24.5 \%, \mathrm{p}<0.05)$ (table 5$)$. When comparing those admitted to cardiology wards versus COE wards, there was no significant difference in the prescription of ACE inhibitors/ARB, ARA or loop diuretics; however, there was a significant increase in the prescription of $\beta$ blockers in those admitted to cardiology wards $(63.9 \%$ vs $42.8 \%, \mathrm{p}<0.05)$ (table 5$)$.

\section{Length of hospital stay}

The median LOS was 7 days for all admissions (table 4). The median LOS was 7 days for patients with a single admission episode and the readmitters group, 7 days for those admitted to COE wards and 10 days for cardiology ward admissions (table 5).

\section{Mortality}

In total, 34 inpatient deaths were recorded $(13 \%)$ and 80 deaths $(30.7 \%)$ were recorded long-term (median follow-up of 307 days for all patients) (table 4). Long-term mortality was significantly lower in patients with a single admission versus readmitters $(22.2 \%$ vs $65.3 \%, \mathrm{p}<0.0001$ ) (table 5). Inpatient mortality and long-term mortality were significantly lower in those managed on cardiology wards versus $\mathrm{COE}$ wards (inpatient mortality $0 \%$ vs $12.9 \%, \mathrm{p}<0.05$ and long-term mortality $8.3 \%$ vs $29.4 \%, \mathrm{p}<0.01$ ) (table 5 ).

\section{Heart failure inpatient review/follow-up arrangements}

Only 2.7\% of admissions managed on a non-cardiology ward had an inpatient heart failure specialist nurse review. Overall, $68.9 \%$ of all admissions had follow-up arrangements, of which $61.9 \%$ were followed up by geriatricians, $17.3 \%$ by cardiology and $20.8 \%$ by other medical specialties. In total, $69.8 \%$ of the single admitters group had follow-up arrangements compared with $65.5 \%$ of the readmitters group.

\section{DISCUSSION}

This retrospective study, which looked at heart failure activity in the elderly in a London university hospital, provides supportive evidence for the poor heart failure outcomes demonstrated by the NHF audit and specifically in the elderly population by the EHFS II. ${ }^{5}$

The patient demographics of this study population is similar to that of other heart failure studies where elderly patients have been studied ${ }^{5}$ and highlights that the presence of comorbidities including hypertension, atrial fibrillation and ischaemic heart disease are

\begin{tabular}{|c|c|c|c|c|c|c|}
\hline $\begin{array}{l}\text { CSHA frailty } \\
\text { scale }\end{array}$ & $\begin{array}{l}\text { Single admitters } \\
(\mathrm{n}=212)(\%)\end{array}$ & $\begin{array}{l}\text { Readmitters } \\
(\mathrm{n}=49)(\%)\end{array}$ & p Value & $\begin{array}{l}\text { COE } \\
(n=201)(\%)\end{array}$ & $\begin{array}{l}\text { Cardiology } \\
(n=36)(\%)\end{array}$ & p Value \\
\hline 1 & 0 & 0 & $\mathrm{NS}^{*}$ & 0 & 0 & $\mathrm{NS}^{*}$ \\
\hline 2 & 0.5 & 2.1 & $\mathrm{NS}^{*}$ & 0.6 & 3.3 & $\mathrm{NS}^{*}$ \\
\hline 3 & 23.4 & 24.5 & $\mathrm{NS}^{*}$ & 26.1 & 20 & $\mathrm{NS}^{*}$ \\
\hline 4 & 35.1 & 32.6 & $\mathrm{NS}^{*}$ & 29.8 & 36.7 & $N^{*}$ \\
\hline 5 & 19.5 & 14.3 & $\mathrm{NS}^{*}$ & 17.3 & 20 & $\mathrm{NS}^{*}$ \\
\hline 6 & 12.2 & 16.3 & $\mathrm{NS}^{*}$ & 14.3 & 16.7 & $\mathrm{NS}^{*}$ \\
\hline 7 & 9.3 & 10.2 & $\mathrm{NS}^{*}$ & 11.9 & 3.3 & $\mathrm{NS}^{*}$ \\
\hline
\end{tabular}

* $p$ Value calculated using 2-tailed Fisher's exact test.

COE, care of elderly; CSHA, Canadian Study of Health and Ageing; NS, not significant. 
Table 4 Comparison of treatments, investigations and outcomes by study

\begin{tabular}{|c|c|c|c|}
\hline & NMUH age $\geq 75$ years $(n=261)$ & NHF audit $2012-2013^{3}(n=36504)$ & EHFS II $\geq 80$ years $^{5}(n=3580)$ \\
\hline Diuretics (\%) & 81.4 (loop only) & 91 (loop only) & 93 \\
\hline ACEi/ARB (\%) & 64.6 & 85 & 76 \\
\hline$\beta$ (\%) Blocker & 49.3 & 82 & 53 \\
\hline ARA (\%) & 28.7 & 49 & 38 \\
\hline Echo $(\%)$ & 23.5 (inpatient only) & 91 & 81 \\
\hline Median LOS & 7 days & 8 days & - \\
\hline \multirow[t]{2}{*}{ Mortality (\%) } & Inpatient-13 & Inpatient-9.4 & Inpatient-10.7 \\
\hline & Median 337 days -30.7 & Median 222 days -15.6 & 12 month -28.4 \\
\hline
\end{tabular}

common in the elderly. Overall, our results also suggest that elderly patients with heart failure are likely to be vulnerable or frail, demonstrating the importance of a multidisciplinary approach to care.

Previously, underuse and underdosage of medications recommended for heart failure have been demonstrated in the elderly population by the EHFS II. ${ }^{5}$ Likewise, this study also shows that a large proportion of patients are not discharged on guidance-indicated treatments. In the NHF audit, age below 75 years was one of the strongest predictors of prescribing evidence-based treatments on discharge, and it is likely that the lower rates of prescribing observed in this study are partly reflective of the older age group studied. The possible reasons for this include a poorer awareness of the use of heart failure treatments in the elderly. Other reasons include the wider prevalence of comorbidities and frailty in the elderly, as demonstrated by the data, and increased side effects from medications, which can significantly limit the use of heart failure treatments in the elderly.

LOS was lower in our study compared with the NHF audit, and this was surprising, as increasing age has been associated with a prolonged LOS in patients with heart failure. ${ }^{3}$ The possible explanations for this include earlier discharge with high follow-up rates in the ambulatory care setting, by geriatricians, as demonstrated by the follow-up data.

An important finding - the high mortality from heart failure-as shown by other studies ${ }^{3}{ }^{5-12}$ is also evident in this study. Inpatient mortality was recorded at $13 \%$, which is higher than that reported by the NHF audit $(9.4 \%)$ and EHFS II (10.7\%). The long-term mortality in this study (median follow-up of 337 days) was also higher than that reported by the NHF audit (median follow-up of 222 days) and other studies. ${ }^{11}$ As increasing age and frailty have been shown to be predictors of mortality, ${ }^{7}$ the higher mortality rates in this study may represent the older, frailer population studied.

One of the most striking findings of this study is that readmission rates among the elderly appear to be markedly high with one-fifth of admissions occurring due to returning patients, mostly within 30 days of discharge. Encouragingly, there was better use of ARAs in the readmitters group compared to the single admitter group; however, this was not replicated for other treatments. This study has also shown that readmitters have less follow-up and increased long-term mortality compared to single admitters, highlighting the need for better community monitoring of heart failure in this group to prevent readmission and to improve

Table 5 Comparison of treatments, investigations and outcomes

\begin{tabular}{|c|c|c|c|c|c|c|}
\hline & $\begin{array}{l}\text { Single admitters } \\
(n=212)(\%)\end{array}$ & $\begin{array}{l}\text { Readmitters } \\
(n=49)(\%)\end{array}$ & p Value & $\begin{array}{l}\text { COE } \\
(n=201)(\%)\end{array}$ & $\begin{array}{l}\text { Cardiology } \\
(n=36)(\%)\end{array}$ & p Value \\
\hline Loop Diuretics & 84.4 & 75.9 & $\mathrm{NS}^{*}$ & 84.6 & 77.8 & $\mathrm{NS}^{*}$ \\
\hline ACEi/ARB & 67.9 & 58.6 & $\mathrm{NS}^{*}$ & 67.1 & 52.8 & $\mathrm{NS}^{*}$ \\
\hline$\beta$ Blocker & 47.2 & 53.4 & NS* & 42.8 & 63.9 & $<0.05^{\star}$ \\
\hline ARA & 24.5 & 36.2 & $<0.05^{\star}$ & 31.8 & 38.9 & $\mathrm{NS}^{*}$ \\
\hline Echo & 26.9 & 17.2 & $\mathrm{NS}^{*}$ & 22.4 & 33.3 & $\mathrm{NS}^{*}$ \\
\hline LVEF & 49.6 & 44.1 & $<0.05 \dagger$ & 48.1 & 44.9 & NS† \\
\hline Median LOS & 7 & 7 & - & 7 & 10 & - \\
\hline \multicolumn{7}{|l|}{ Mortality } \\
\hline Inpatient & 12.3 & 16.3 & $\mathrm{NS}^{*}$ & 12.9 & 0 & $<0.05^{\star}$ \\
\hline Median 337 days & 22.2 & 65.3 & $<0.0001^{*}$ & 29.4 & 8.3 & $<0.01^{\star}$ \\
\hline
\end{tabular}


outcomes. Interestingly, there were no significant differences in comorbidities or clinical frailty between single admitters and readmitters. LVEF, however, was significantly lower in the readmitters group, suggesting the use of LVEF in identifying patients who have a higher risk of readmission and carry a worse prognosis.

As with the NHF audit, this study has also identified key differences in heart failure management and patient outcomes between those managed on $\mathrm{COE}$ and cardiology wards. For example, like the NHF audit, a greater percentage of patients admitted to cardiology wards underwent inpatient echocardiography, suggesting poorer access to specialist investigations by COE teams. A lower percentage of patients on COE teams were also discharged on $\beta$ blockers, as with the NHF data. ${ }^{3}$ This finding may partly be explained by the fact that chronic obstructive pulmonary disease was more common in the COE group, although this did not reach statistical significance. Another key finding was the significantly increased mortality in those managed on COE wards versus cardiology wards, and although our data have not been adjusted for age, sex, aetiology, symptoms, treatment and investigations, a similar outcome has also been identified in the NHF audit where such adjustments were made.

This study has a number of limitations. First, patient outcomes, such as treatment on discharge and echocardiography, may be under-represented through selection bias, as all patients without a discharge medication summary were excluded from the study, and only inpatient echocardiography, the data of which were available, was looked at. Mortality data in this study may also be under-represented due to the small population size. To improve the validity of our study and to look at the influence of social class/geographical differences on heart failure in the elderly, a larger multicentre study would need to be performed.

In summary, this study has shown that investigation and treatment for heart failure in the elderly can be improved, that readmission rates and mortality remain high and that access to specialist cardiology input is associated with better outcomes in terms of treatment and mortality. Clearly, this highlights the need for a change in the delivery of heart failure care in the elderly. This should start with the initial assessment, as the efficacy of rapid access heart failure clinics in providing a rapid assessment, diagnosis and early introduction of recommended treatments has been demonstrated previously. ${ }^{13}$ In the hospital setting, geriatricians and cardiologists should follow the lead taken by acute myocardial infarction to ensure that there are improvements in the access of older patients to recommended investigations and treatments, if tolerated. Following the success from acute stroke management, this could be implemented on a designated heart failure unit where geriatricians and cardiologists would work as part of a multidisciplinary team. Finally, much more needs to be done in the community setting to improve heart failure outcomes, including better integration of community and secondary care services. The role of community heart failure teams in reducing readmission and improving mortality has also been well documented in retrospective cohort studies ${ }^{14}$ and randomised controlled trials, ${ }^{15} 16$ and thus there should be greater involvement of specialist heart failure teams working alongside geriatricians in the outpatient setting.

\section{Competing interests None declared.}

Provenance and peer review Not commissioned; externally peer reviewed.

Open Access This is an Open Access article distributed in accordance with the Creative Commons Attribution Non Commercial (CC BY-NC 4.0) license, which permits others to distribute, remix, adapt, build upon this work noncommercially, and license their derivative works on different terms, provided the original work is properly cited and the use is non-commercial. See: http:// creativecommons.org/licenses/by-nc/4.0/

\section{REFERENCES}

1. McMurray JJ, Stewart S. Epidemiology, aetiology, and prognosis of heart failure. Heart 2000;83:596-602.

2. McMurray JJ, Adamopoulos S, Anker SD, et al. ESC guidelines for the diagnosis and treatment of acute and chronic heart failure 2012: the task force for the diagnosis and treatment of acute and chronic heart failure 2012 of the European Society of Cardiology. Developed in collaboration with the Heart Failure Association (HFA) of the ESC. Eur Heart J 2012;33:1787-847.

3. National Heart Failure Audit, April 2012-March 2013. http:// wwwuclacuk/nicor/audits/heartfailure/documents/annualreports/ hfannual12-13pdf (accessed 24 Jan 2015).

4. Management of chronic heart failure in adults in primary and secondary care. National Institute for Health and Clinical Excellence 2010. https://wwwniceorguk/guidance/cg108/resources/ guidance-chronic-heart-failure-pdf (accessed 24 Jan 2015).

5. Komajda M, Hanon O, Hochadel M, et al. Contemporary management of octogenarians hospitalized for heart failure in Europe: Euro Heart Failure Survey II. Eur Heart J 2009;30:478-86.

6. Baxter J, McDonagh T. Can geriatricians improve inpatient heart failure care? Time for a heart to heart. Age Ageing 2012;41:140-1.

7. Rockwood K, Song X, MacKnight C, et al. A global clinical measure of fitness and frailty in elderly people. CMAJ 2005;173:489-95.

8. Cleland JG, McDonagh T, Rigby AS, et al. The national heart failure audit for England and Wales 2008-2009. Heart 2011;97:876-86.

9. Cleland JG, Swedberg K, Follath F, et al. The Euro Heart Failure survey programme-a survey on the quality of care among patients with heart failure in Europe. Part 1: patient characteristics and diagnosis. Eur Heart J 2003;24:442-63.

10. Nicol ED, Fittall B, Roughton M, et al. NHS heart failure survey: a survey of acute heart failure admissions in England, Wales and Northern Ireland. Heart 2008;94:172-7.

11. Cowie MR, Wood DA, Coats AJ, et al. Survival of patients with a new diagnosis of heart failure: a population based study. Heart 2000;83:505-10.

12. Mehta PA, Dubrey SW, Mclntyre HF, et al. Improving survival in the 6 months after diagnosis of heart failure in the past decade: population-based data from the UK. Heart 2009;95:1851-6.

13. Fox KF, Cowie MR, Wood DA, et al. A Rapid Access Heart Failure Clinic provides a prompt diagnosis and appropriate management of new heart failure presenting in the community. Eur $J$ Heart Fail 2000;2:423-9.

14. Ezekowitz JA, van Walraven C, McAlister FA, et al. Impact of specialist follow-up in outpatients with congestive heart failure. CMAJ 2005;172:189-94.

15. Stromberg A, Martensson J, Fridlund B, et al. Nurse-led heart failure clinics improve survival and self-care behaviour in patients with heart failure: results from a prospective, randomised trial. Eur Heart $J$ 2003;24:1014-23.

16. Blue L, Lang E, McMurray JJ, et al. Randomised controlled trial of specialist nurse intervention in heart failure. BMJ 2001;323:715-18. 